\title{
A DIMENSÃO DO VISUAL EM CLARICE LISPECTOR
}

\author{
Mariana Silva Bijotti ${ }^{1}$
}

\begin{abstract}
Resumo
Este artigo visa comparar a visualidade em dois textos de Clarice Lispector: a crônica "Medo da libertação" e o romance A paixão segundo G.H. - a partir do mural de Janair. Em ambas as obras, as modalidades visuais presentes parecem ter um papel importante para as narradoras, no reconhecimento de si mesmas, do outro e do mundo burguês que as aprisiona, podendo, assim, concedê-las a força necessária para seguir o caminho da (temível) libertação.
\end{abstract}

\section{Palavras-chave}

Clarice Lispector. Visualidade. Alteridade. A paixão segundo G.H.. "Medo da libertação"

Conforme exposto por Carlos Mendes de Sousa em seu livro Clarice Lispector: Pinturas, a escritora, em entrevista a Cristina Autran, quando esta lhe pede para fazer seu autorretrato, aponta para cinco quadros diferentes em suas paredes, mostrando seus retratos pintados por artistas diversos. Sousa, ao mencionar esse fato, faz uma afirmação interessante: "quando instigada a apresentar o seu autorretrato, Clarice aponta para os quadros onde está representada. Trata-se de um trânsito idêntico ao das declarações de autores que preferem não falar sobre o que escreveram. O que escreveram é que fala por eles" (SOUSA, 2013, p. 35).

Clarice, além de escritora, também se aventurava na pintura, apesar dela mesma não se considerar como uma pintora, nem considerar seus quadros como obras de arte por isso, talvez, sua preferência em mostrar os retratos que os outros fizeram sobre ela, ao invés dela própria fazer seu autorretrato. Em "Literatura de vanguarda no Brasil”, texto que ela escrevera para ler em conferências, ela afirma:

O que me "descontrai", por incrível que pareça, é pintar, e não ser pintora de forma alguma, e sem aprender nenhuma técnica. Pinto tão mal que dá gosto e não mostro meus, entre aspas, "quadros" a ninguém. É relaxante e ao mesmo tempo excitante mexer com cores e formas, sem compromisso com coisa alguma. É a coisa mais pura que faço. (LISPECTOR, 2005, p. 110)

\footnotetext{
1 Mestre em Literatura Brasileira pela FFLCH - USP (2020), com dissertação intitulada "Moldar o inexpressivo: a formação do artista em Clarice Lispector e a escrita escultórica em A paixão segundo G.H.”. Graduada em Letras (Português e Inglês - bacharelado e licenciatura) pela mesma instituição.
} 
A pintura e o desenho, inclusive, aparecem frequentemente nas narrativas clariceanas. Em crônicas, essa arte visual representa, muitas vezes, o desejo de Clarice em abandonar a escrita, se para isso ela tivesse o dom e a vocação necessários:

\begin{abstract}
A verdade é que simplesmente me faltou o dom para a minha verdadeira vocação: a de desenhar. Porque eu poderia, sem finalidade nenhuma, desenhar e pintar um grupo de formigas andando ou paradas - e sentirme inteiramente realizada nesse trabalho. Ou desenharia linhas e linhas, uma cruzando a outra, e me sentiria toda concreta nessas linhas que os outros talvez chamassem de abstratas. (...)

Eu falaria sobre frutas e frutos. Mas como quem pintasse com palavras. Aliás, verdadeiramente, escrever não é quase sempre pintar com palavras? (LISPECTOR, 1999, p. 197-198)
\end{abstract}

Pintar (ou desenhar) e escrever aparecem lado a lado. Nota-se como Clarice revela sua aspiração em fazer uma arte sem o intermédio da palavra, impossível justamente pela falta de dom à sua verdadeira vocação: o desenho. Mesmo assim, caso ela se enveredasse nos caminhos dessa arte, sua reflexão ainda envolveria o objeto principal do escritor, a palavra - "como quem pintasse com palavras" -, aproximando, portanto, pintura da escrita. Se, para Clarice, escrever "é quase sempre pintar com palavras", é possível interpretar como a autora parece demonstrar uma reflexão artística a respeito do desfalque das fronteiras entre a arte visual e a verbal.

Em outras crônicas, o mesmo tema reaparece:

Ao escrevê-lo, de novo a certeza só aparentemente paradoxal de que o que atrapalha ao escrever é ter de usar palavras. É incômodo. É como se eu quisesse uma comunicação mais direta, uma compreensão muda como acontece às vezes entre pessoas. Se eu pudesse escrever por intermédio de desenhar na madeira ou de alisar uma cabeça de menino ou de passear pelo campo, jamais teria entrado pelo caminho da palavra. Faria o que tanta gente que não escreve faz, e exatamente com a mesma alegria e o mesmo tormento de quem escreve, e com as mesmas profundas decepções inconsoláveis: viveria, não usaria palavras. $\mathrm{O}$ que pode vir a ser a minha solução. Se for, bem-vinda. (LISPECTOR, 1999, p. 285-286)

O subjuntivo comparece com força neste trecho, a fim de manifestar a hipótese de uma realidade na qual a escritora pudesse viver sem usar palavras. Dentre as alternativas para substituição da escrita, há o "desenhar na madeira”. O desenho e a pintura são artes que, para Clarice, possuem uma "comunicação mais direta" exatamente por não 
precisarem do desagradável intermédio verbal - este, que é paradoxalmente uma "maldição, mas uma maldição que salva":

Eu disse uma vez que escrever é uma maldição. Não me lembro por que exatamente eu o disse, e com sinceridade. Hoje repito: é uma maldição, mas uma maldição que salva.

(...) É uma maldição porque obriga e arrasta como um vício penoso do qual é quase impossível se livrar, pois nada o substitui. E é uma salvação. Salva a alma presa, salva a pessoa que se sente inútil, salva o dia que se vive e que nunca se entende a menos que se escreva. Escrever é procurar entender, é procurar reproduzir o irreproduzível, é sentir até o último fim o sentimento que permaneceria apenas vago e sufocador. Escrever é também abençoar uma vida que não foi abençoada. (LISPECTOR, 1999, p. 134)

A escrita também é vista, outras vezes, de forma primorosa, contrariando as ideias demonstradas nos trechos de crônicas anteriores - de que a primeira escolha de Clarice seria pelas artes visuais, caso ela possuísse os atributos necessários -: "O contato com o outro ser através da palavra escrita é uma glória. Se me fosse tirada a palavra pela qual tanto luto, eu teria que dançar ou pintar. Alguma forma de comunicação com o mundo eu daria um jeito de ter. E escrever é um divinizador do ser humano" (LISPECTOR, 1999, p. 96). Agora, a pintura aparece como uma segunda opção, na falta de possibilidade da escrita, sua arte primária e dignificante.

Contudo, a pintura não comparece só nessas crônicas nas quais a autora reflete a respeito das probabilidades em mudar de arte, seguindo seu desejo pelo não uso da palavra; ou, ainda, sobre as desavenças entre a pintura e a escrita. É interessante notar, também, como essa modalidade artística desponta, por vezes, um conhecimento sobre si, sobre o outro e sobre o mundo no geral. É o que se pode observar em outra crônica, intitulada "Medo da libertação", retomada na íntegra:

\section{Medo da libertação}

Se eu me demorar demais olhando Paysage aux Oiseaux Jaunes (Paisagem com Pássaros Amarelos, de Klee), nunca mais poderei voltar atrás. Coragem e covardia são um jogo que se joga a cada instante. Assusta a visão talvez irremediável e que talvez seja a da liberdade. O hábito que temos de olhar através das grades da prisão, o conforto que traz segurar com as duas mãos as barras frias de ferro. A covardia nos mata. Pois há aqueles para os quais a prisão é a segurança, as barras um apoio para as mãos. Então reconheço que conheço poucos homens livres. Olho de novo a paisagem e de novo reconheço que covardia e liberdade estiveram em jogo. A burguesia total cai ao se olhar Paysage aux Oiseaux Jaunes. Minha coragem, inteiramente possível, me amedronta. 
Começo até a pensar que entre os loucos há os que não são loucos. E que a possibilidade, a que é verdadeiramente, não é para ser explicada a um burguês quadrado. E à medida que a pessoa quiser explicar se enreda em palavras, poderá perder a coragem, estará perdendo a liberdade. Les Oiseaux Jaunes não pede sequer que se o entenda: esse grau é ainda mais liberdade: não ter medo de não ser compreendido. Olhando a extrema beleza dos pássaros amarelos calculo o que seria se eu perdesse totalmente o medo. $\mathrm{O}$ conforto da prisão burguesa tantas vezes me bate no rosto. E, antes de aprender a ser livre, tudo eu aguentava - só para não ser livre. (LISPECTOR, 1999, p. 198)

A pintura aparece, aqui, a partir da referência ao quadro Paisagem com pássaros amarelos, de Paul Klee, datado de 1923. A narradora, agora, posiciona-se não mais como uma comentadora a respeito das diversas artes, mas como uma observadora e apreciadora artística: vislumbrando a obra em questão, a narradora da crônica se reconhece, tal qual pássaros em uma gaiola, presa dentre as confortáveis barras da prisão burguesa.

O que nos leva ao poder da arte: a emancipação. E é justamente pelo plano visual que essa emancipação pode ocorrer: tantas vezes, na crônica, é repetido o verbo “olhar", com suas variantes flexionais - retomando um dos trechos: "Olhando a extrema beleza dos pássaros amarelos calculo o que seria se eu perdesse totalmente o medo. O conforto da prisão burguesa tantas vezes me bate no rosto" (meus grifos). É a partir desse ato de ver - no caso, ver uma obra de arte - que a narradora pode, enfim, dar-se conta dessa prisão burguesa que a aprisiona e, consequentemente, talvez conseguir perder o medo de libertar-se. É possível notar, aqui, o que a crítica já chamou de poética do olhar de Clarice Lispector. Segundo Regina Pontieri, “a gênese da escritura clariciana se dá como simultaneidade e/ou cruzamento de visão e oralidade" (PONTIERI, 2001, p. 223), ou seja, do olhar e da sua verbalização na escrita. Ainda:

Desde as primeiras obras de Clarice Lispector, o olhar aparece como instrumento por excelência de um conhecimento que se faz como autoconhecimento. Olhar atento e demorado; que não mantém o vidente à distância do visível mas que, ao contrário, localiza-os na mesma carne do real. (PONTIERI, 2001, quarta capa)

O conhecimento de algo outro a partir do olhar, então, torna-se autoconhecimento, aproximando aquele que olha daquilo que é olhado - e essa experiência é, depois, reformulada verbalmente, com a arte da palavra. É o que parece ocorrer em "Medo da libertação". A própria Clarice, de alguma forma, parece explicar essa sua poética: “a visão (...) altera a realidade, construindo-a. Uma casa não é construída apenas com pedras, 
cimento, etc. O modo de olhar de um homem também a constrói” (LISPECTOR, 1984, p. 416 apud PONTIERI, 2001, p. 18). Na crônica em questão, a visão dos pássaros no quadro pode alterar a realidade da observadora-narradora, permitindo-a construí-la de outra maneira, calculando como seria viver diferentemente do que ela vivia até então, na prisão burguesa. Ou, o quadro Paisagem com pássaros amarelos (e pode-se estender isso para toda arte visual) não é construído apenas com a tinta e outros materiais do pintor, mas também com o modo de olhar da observadora dessa obra. Assim, parece ser esse jogo do olhar que intriga Lispector a respeito das artes visuais: sem o intermédio da palavra, as modalidades artísticas que atraem primordialmente a visão - desenho, pintura e até escultura - são, claramente, mais efetivas no que concerne essa relação estritamente visual que se quer estabelecer entre quem vê e quem/o que é visto. Esse interesse não é exposto apenas em suas personagens de romances (como a protagonista de A paixão segundo G.H., uma escultora; a narradora-pintora de Água viva e a pintora Ângela Pralini de Um sopro de vida), em contos ou crônicas, mas também na própria autora, como já mencionado, que dizia pintar "quadros", descompromissadamente, sem a obrigatoriedade de seguir nenhuma técnica ou estilo uma vez que ela não possuía, conforme suas próprias palavras, o dom e a vocação necessários para ser pintora - por isso, a pureza dessa atividade, experimental para ela.

Voltando à análise de "Medo da libertação", a partir, portanto, desse jogo do olhar com a pintura de Paul Klee, que pode levar a personagem ao vislumbre da quebra das barras da prisão burguesa, nota-se o perigo do "vertiginoso relance", conforme denominado por Gilda de Mello e Souza, assombrando igualmente essa narradora da crônica; como também se revela em inúmeros romances e contos clariceanos, sendo um dos temas principais de Clarice, como já amplamente estudado pela crítica. Se a prisão burguesa é a segurança, pois assim se estaria pertencendo ao mundo que nos cerca - outro desejo clariceano, o de consistir seu espaço na sociedade: “A vida me fez de vez em quando pertencer, como se fosse para me dar a medida do que eu perco não pertencendo. E então eu soube: pertencer é viver" (LISPECTOR, 1999, p. 112) -, a libertação é uma condição temerosa, pois, além de posicionar a narradora em uma "solidão de não pertencer" (LISPECTOR, 1999, p. 112), pode fazê-la perder a sua proteção habitual e o seu papel efetivo na sociedade. Como a personagem Ana em "Amor" - que, mesmo enxergando por alguns momentos sem as lentes sociais que a cegavam, prefere voltar à sua vida corriqueira com o marido, os filhos e o cuidado com o lar -, a narradora de "Medo da libertação" parece também possuir certa preferência em participar desse mundo 
previamente conhecido e limitado pela burguesia e seus princípios. No entanto, a narradora dessa crônica acaba por reconhecer a própria covardia ante a escolha da facilidade em participar desse mundo ao invés de desfazer-se finalmente dele - apesar de tantas vezes esse conforto burguês "bater no rosto" da personagem, como ocorre no momento em que ela vê a pintura de Klee, ela diz aguentar de tudo "só para não ser livre".

Tudo isso sendo pensado, então, a partir da apreciação de uma obra de arte visual, a qual de fato existe na realidade, e que é remontada no texto para demonstrar a reflexão da narradora acerca de sua própria falta da (amedrontosa) liberdade. Como dito anteriormente, o assunto da liberdade e do confronto com o mundo previamente conhecido é recorrente na obra clariceana. E essa defrontação pode ser trazida, justamente, pela arte, como no caso de Paisagem com pássaros amarelos. Outro texto de Clarice apresenta, a sua maneira, a manifestação artística visual também como uma forma de perceber o conflito do eu com o mundo que o cerca, iluminando o sujeito com uma amostra de libertação: A paixão segundo G.H..

A protagonista G.H. (que, relembrando, é uma escultora), após a demissão da empregada Janair, decide limpar o quarto que lhe era destinado. Pensando na condição possivelmente esquálida que perpetuaria esse cômodo, a personagem toma seu primeiro susto: ao adentrar o ambiente, ela vê como o quarto estava, na verdade, limpo e organizado. O seu segundo susto vem após essa entrada no local, ao perceber que nele Janair havia deixado um desenho: um mural contendo três seres - uma mulher, um homem e um cachorro:

Na parede caiada, contígua à porta - e por isso eu ainda não tinha o visto - estava quase em tamanho natural o contorno do carvão de um homem nu, de uma mulher nua, e de um cão que era mais nu do que um cão. (...) eram os contornos de uma nudez vazia. O traço era grosso, feito com ponta quebrada de carvão. Em alguns trechos o risco se tornava duplo como se um traço fosse o tremor do outro. Um tremor seco de carvão seco.

A rigidez das linhas incrustava as figuras agigantadas e atoleimadas na parede, como de três autômatos. (...) O malfeito do traço excessivamente firme tornava o cachorro uma coisa dura e petrificada, mais engastada em si mesmo do que na parede.

Passada a primeira surpresa de descobrir em minha própria casa o mural oculto, examinei melhor, dessa vez com surpresa divertida, as figuras soltas na parede. Os pés simplificados não chegavam a tocar na linha do chão, as cabeças pequenas não tocavam a linha do teto (...).

Nenhuma figura tinha ligação com a outra, e as três não formavam um grupo: cada figura olhava para a frente, como se nunca tivesse olhado para o lado, como se nunca tivesse visto a outra e não soubesse que ao lado existia alguém. 
(...) cada figura se achava ali na parede exatamente como eu mesma havia permanecido rígida de pé à porta do quarto. $\mathrm{O}$ desenho não era um ornamento: era uma escrita. (...) (LISPECTOR, 2009, p. 38-39)

O desenho de Janair espanta G.H., pela ousadia da mulher em tê-lo deixado na parede e pelo conteúdo retratado. À semelhança das pinturas rupestres, como já apontado pelos críticos - "A arte rupestre, de Altamira e Lascaux, comparece quando G.H. imagina o 'mural' como uma representação pré-histórica dela mesma" (OLIVEIRA, 1993, p. 85) -, Janair parece traçar não apenas as simples formas humanas e canina, mas também, de acordo com a perspectiva da protagonista acerca desse desenho, uma crítica à forma de vida de G.H., a qual, aparentemente, nunca havia prestado a devida atenção ao outro, principalmente o de classe menos privilegiada, como Janair. Assim, G.H. demonstraria uma semelhança com as figuras que estavam representadas, as quais pareciam se comportar "como se nunca tivesse olhado para o lado, como se nunca tivesse visto a outra e não soubesse que ao lado existia alguém” (LISPECTOR, 2009, p. 38-39). É válido lembrar que a protagonista, no início, diz não se lembrar da fisionomia da ex-empregada - "A lembrança da empregada ausente me coagia. Quis lembrar-me de seu rosto, e admirada não consegui (...). A lembrança de sua cara fugia-me, devia ser um lapso temporário" (LISPECTOR, 2009, p. 39).

Até o momento em que vê o desenho na parede, instante o qual faz a protagonista rememorar essa outra que frequentava sua casa:

Mas seu nome - é claro, é claro, lembrei-me finalmente: Janair. E, olhando o desenho hierático, de repente me ocorria que Janair me odiara. Eu olhava as figuras de homem e mulher que mantinham expostas e abertas as palmas das mãos vigorosas, e que ali pareciam ter sido deixadas por Janair como mensagem bruta para quando eu abrisse a porta. (...)

Foi quando inesperadamente consegui rememorar seu rosto, mas é claro, como pudera esquecer? Revi o rosto preto e quieto, revi a pele inteiramente opaca que mais parecia um de seus modos de se calar, as sobrancelhas extremamente bem desenhadas, revi os traços finos e delicados que mal eram divisados no negror apagado da pele.

Os traços - descobri sem prazer - eram traços de rainha. E também a postura: o corpo ereto, delgado, duro, liso, quase sem carne, ausência de seios e de ancas. E sua roupa? Não era de surpreender que eu a tivesse usado como se ela não tivesse presença: sob o pequeno avental, vestiase sempre de marrom escuro ou de preto, o que a tornava toda escura e invisível - arrepiei-me ao descobrir que até agora eu não havia percebido que aquela mulher era uma invisível. Janair tinha quase que apenas a forma exterior, os traços que ficavam dentro de sua forma eram tão apurados que mal existiam: ela era achatada como um baixo-relevo preso a uma tábua. (LISPECTOR, 2009, p. 39-40) 
G.H. parece tentar retirar de si a culpa pela invisibilidade do outro, como quando lembra que Janair, uma mulher negra, "vestia-se sempre de marrom escuro ou de preto", tornando-se literalmente imperceptível; ou quando nota que os traços de Janair "mal existiam", tornando-a achatada, praticamente irrelevante. Todavia, o mural deixado pela empregada faz com que G.H. não se esqueça de quem a outra era. E rememorando Janair, ao observar o mural, ela própria se reconhece nos personagens deixados pela empregada:

Eu olhava as figuras de homem e mulher que mantinham expostas e abertas as palmas das mãos vigorosas, e que ali pareciam ter sido deixadas por Janair como mensagem bruta para quando eu abrisse a porta.

Meu mal-estar era de algum modo divertido: é que nunca antes me ocorrera que, na mudez de Janair, pudesse ter havido uma censura à minha vida, que devia ter sido chamada pelo seu silêncio de "uma vida de homens"? como me julgara ela?

Olhei o mural onde eu devia estar sendo retratada... Eu, o Homem. E quanto ao cachorro - seria este o epíteto que ela me dava? Havia anos que eu só tinha sido julgada pelos meus pares e pelo meu próprio ambiente que eram, em suma, feitos de mim mesma e para mim mesma. Janair era a primeira pessoa realmente exterior de cujo olhar eu tomava consciência. (...)

E fatalmente, assim como ela era, assim deveria ter me visto? abstraindo daquele meu corpo desenhado na parede tudo o que não era essencial, e também de mim só vendo o contorno. No entanto, curiosamente, a figura na parede lembrava-me alguém, que era eu mesma. (LISPECTOR, 2009, p. 39-40)

É possível notar como G.H. parece perceber, então, o ponto de vista de um outro, de classe social mais baixa, acerca de sua vida essencialmente burguesa, compondo, assim, a relação de "identidade/alteridade social” que Daniela Kahn, em A via crucis do outro: identidade e alteridade em Clarice Lispector, categorizou a respeito de algumas obras clariceanas: a partir da visão do outro, tem-se a visão de si mesma. Aqui, ainda, pode-se pensar de outra maneira: a partir da manifestação artística do outro, G.H. pode refletir sobre seu próprio modo de vida. Retomando, de alguma forma, a dimensão psicanalítica no campo da arte, do olhar e da imagem, conforme Georges Didi-Huberman: "O que vemos só vale - só vive - em nossos olhos pelo que nos olha" (HUBERMAN, 2010, p. 29); e, portanto, "o ato de ver só se manifesta ao abrir-se em dois" (HUBERMAN, 2010, p. 29): o que vemos e o que nos olha. O desenho na parede, ao passo em que a narradora o observa, também olha G.H., já que esse mural refletiria a si mesma, podendo reforçar, assim, a relação de alteridade: ela se reconhece na figura do 
homem desenhado, e interpreta o cachorro como sendo seu epíteto - talvez um modo de Janair mostrá-la como ela segue lealmente o que lhe é imposto, da mesma forma que um cão domado: no caso de G.H., a vida luxuosa da alta burguesia, em seu ostensivo apartamento - “O apartamento me reflete. É no último andar, o que é considerado uma elegância. Pessoas de meu ambiente procuram morar na chamada 'cobertura'. É bem mais que uma elegância" (LISPECTOR, 2009, p. 29) -, não refletindo sobre isso, mas apenas vivendo de acordo com o que lhe é demandado ou esperado; como um animal domesticado que, ao invés de seguir seus instintos e sua independência, contenta-se com a vida que lhe é ensinada a viver: "Essa coisa sobrenatural que é viver. O viver que eu havia domesticado para torná-lo familiar” (LISPECTOR, 2009, p. 16, grifos meus). Semelhantemente à narradora de "Medo da libertação", que parece se contentar com a prisão burguesa ao invés de destruí-la para emancipar-se.

No entanto, diferentemente da crônica em questão, o mural de Janair parece de fato iniciar, em G.H., o seu próprio processo de libertação, culminando na comunhão com a barata - episódio no qual, diz Pontieri, "Clarice não se contenta com olhar insistente e atentamente o mundo: quer comê-lo, como modo radical de a ele se entregar. Ver o outro, diz G.H., pode significar 'comer o outro'” (2001, p. 21-22) - e na consequente desumanização de si mesma. Segundo Solange Ribeiro de Oliveira, esse terceiro episódio de espanto de G.H., a visão da barata, bem como o resultado desse encontro (a ingestão do impuro) poderiam ter sido, ainda, motivados pelo ódio de classe que a protagonista parece demonstrar em relação a Janair - já que, logo após o vislumbre do desenho, ela diz ter sentido "Uma cólera inexplicável, mas que me vinha toda natural, me tomara: eu queria matar alguma coisa ali" (LISPECTOR, 2009, p. 43):

\footnotetext{
O que irrita G.H. acima de tudo é que a censura muda que lê no desenho fora expressada por alguém de uma classe social inferior (...).

Esse ódio impessoal é, evidentemente, o ódio do opressor pelo oprimido, o ódio entre a que nunca teve privilégios e a que temia perder os que sempre tivera. (...)

No desenho - ou na mente de G.H. - patroa e empregada agora se defrontam pela primeira vez e seu encontro é de puro ódio. G.H. usa diversas vezes o demonstrativo "aquela" ("aquela empregada"), com sua conotação emocional de desprezo e ódio. (OLIVEIRA, 1996, p. 345)
}

Assim, é graças ao outro, o infamiliar e estranho, antes tão ignorado (e também temido), que G.H. pode, por fim, enxergar seu modo de vida e alterá-lo: primeiramente, Janair; depois, o espelho da empregada: a barata - 
"É que ali dentro de minha casa se alojara, a estrangeira, a inimiga indiferente". Assim G.H. refere-se à empregada Janair, duplo desse outro estranho que é a barata, habitante pré-histórico de seu quarto, templo sagrado dessa aventura em direção às próprias origens.

A repercussão dessa "infamiliaridade" da barata, condensação simbólica do inconsciente como lugar do Outro em nós, invade o cenário do conto e da psique de G.H. (...)

Como quer Freud no ensaio sobre "O Estranho" (1919), o elemento que amedronta aponta para o retorno do reprimido, sugerindo que algo conhecido e familiar deveria permanecer secreto mas veio à luz. É esse material sinistro e perturbador que move o romance (...). (ROSENBAUM, 2006, p. 147-148)

Dessa forma, eis o que significa de fato a paixão de G.H.:

O ethos da paixão de G.H. (...) Trata-se de perder o poder fálico sobre o outro, desaprender um olhar viciado sobre as coisas, implodir um edifício bem arrumado e sucumbir ao domínio do desconhecido. Agora é a barata que engessa G.H., em seu instante de torpor e horror, impedindo-a de avançar e movimentar-se de novo na busca do refúgio e comodidade. A barata, na sua impersonalidade soberba, com sua força nadificante, quebra sadicamente o invólucro da persona G.H. (ROSENBAUM, 2006, p. 149).

A barata - e, antes dela, o mural de Janair - fazem, neste romance, o papel da Paisagem com pássaros amarelos, de Klee, em "Medo da libertação". Uma vez que, para Clarice, pintura e escrita teriam funções semelhantes, já que, segundo sua concepção, tanto escrever quanto pintar poderiam ser interpretados como "pintar com palavras" (LISPECTOR, 1999, p. 196-198), pode-se analisar tanto o quadro de Klee quanto o mural de Janair também como espécies de escritas, mas escritas puramente visuais, sem o intermédio da palavra - como a própria escritora parecia, por vezes, desejar. Ambos tratam de ensinar algo aos seus espectadores, oferecendo-lhes um aprendizado, como se nessas obras plásticas houvessem, realmente, palavras grafadas que pudessem levar diretamente os observadores às suas respectivas reflexões - de forma que essas obras, ao serem vistas, também vissem o observador, quase dialogando com ele, tal qual a perspectiva do próprio Paul Klee acerca do olhar e, portanto, do pintar:

Numa floresta, repetidas vezes senti que não era eu que olhava a floresta. Em certos dias senti que eram as árvores que olhavam para mim, que me falavam... Eu lá estava escutando... Creio que o pintor deve ser traspassado pelo universo, e não querer traspassá-lo... Aguardo ser interiormente submergido, sepultado. Pinto, talvez, para ressurgir. 
(MERLEAU-PONTY, 1975, p. 283 apud PONTIERI, 2001, p. 185, grifos meus)

Além disso, o próprio desenho de Janair é descrito de forma a amalgamar, de certa maneira, a arte visual e a verbal: "O desenho não era um ornamento: era uma escrita" (LISPECTOR, 2009, p. 39). Analogamente, Mário de Andrade parece ter a mesma perspectiva sobre esse tipo de arte:

O que me agrada principalmente na tão complexa natureza do desenho, é o seu caráter infinitamente subtil, de ser ao mesmo tempo uma transitoriedade e uma sabedoria. $O$ desenho fala, chega mesmo a ser muito mais um espécie de escritura, uma caligrafia, que uma arte plástica (ANDRADE, 1965, p. 71, grifos meus)

Ainda, o desenho de Janair, por se aproximar das pinturas rupestres, pode possibilitar uma maior afinidade entre arte e realidade, conforme apontado por Rosenbaum ao revisitar Arnold Hauser:

Temos, então, uma alusão clara à arte primitiva do período paleolítico, caracterizada pelo gesto mágico do artista que, ao pintar um animal, aprisionava-o na realidade. Trata-se de acenar para a indiscriminação entre o mundo da mimesis, da representação, e o mundo da realidade empírica, anulando a descontinuidade inevitável entre ambos. Aprofundemos um pouco mais essa noção a partir da definição de Arnold Hauser:

As pinturas faziam parte da técnica deste processo de magia; eram a "ratoeira" em que a caça havia de cair, ou a ratoeira com o animal já capturado. É que os desenhos constituíam simultaneamente a representação e a coisa representada; eram simultaneamente o desejo e a realização do desejo. O caçador e o pintor da era paleolítica supunham encontrar-se na posse do próprio objeto desde que possuíssem a sua imagem; julgavam adquirir poder sobre o objeto por intermédio da sua representação.

Portanto, a imagem é a coisa, a escrita é o real, anulando-se o intervalo e a distância inevitáveis ao ato de representar. (ROSENBAUM, 2006, p. 159)

Outro aspecto do desenho de Janair que deixaria G.H. em cólera: a posse e, portanto, o poder que a empregada teria sobre a protagonista, ao desenhá-la na parede, rompendo com a distinção entre realidade e obra, como acreditado pelo homem da préhistória que aprisionava, pelas pinturas, os animais nas suas cavernas. G.H., que pensava estar acima da empregada, crendo possuir maior controle sobre ela do que o contrário, 
descobre-se representada pelo outro pertencente às classes desfavorecidas, e é justamente na arte que esse outro conquistaria poder e autoridade. Ainda, é por essa manifestação artística que uma outra "prisão" seria criada: a do objeto representado pelo sujeito que o representa - G.H. ficara presa por Janair a partir do momento em que se vê como os seres da parede de sua própria "caverna".

Mas, paradoxalmente, essa prisão do outro sobre si é o que pode levar à libertação. Ao contrário da prisão burguesa, que enclausura G.H. e a narradora da crônica em questão. Ser aprisionado pelo outro através da arte não traria consequências de limitação do sujeito frente ao mundo em que ele vive. Na verdade, ser captado pelo outro é o que pode fazer com que alguém, finalmente, ganhe consciência sobre si e sobre o mundo, como é o caso (mesmo que diferente entre ambos) das duas protagonistas das narrativas estudadas aqui - e, no caso específico de G.H., pode fazer com que ela, justamente, perca esse "poder fálico" sobre a outra de menor classe, como refletiu Rosenbaum. G.H. é, de fato, captada por Janair em sua pintura, estando representada no desenho; a narradora de "Medo da libertação" não está representada na obra de Klee, mas se deixa captar (ou ser olhada) por ela, esclarecendo seu medo de "se demorar demais olhando Paysage aux Oiseaux Jaunes" e "nunca mais poder voltar atrás" (LISPECTOR, 1999, p. 198), em seu mundo previamente conhecido, que era a sua clausura.

Assim, é possível interpretar, nessas duas narrativas, como o desenho/a pintura do outro é inserida como elemento de uma possível libertação: parece ser isso que o mural de Janair e Paysage aux Oiseaux Jaunes proporcionam às suas respectivas observadoras. Parece, inclusive, que G.H. e a narradora da crônica poderiam ser até a mesma pessoa: assustadas com a visão da liberdade; aceitando o conforto reconhecido na prisão social; reconhecendo, com as pinturas, a burguesia em jogo; descobrindo em si uma coragem anteriormente encoberta e domada. E mais ainda: a aceitação (mesmo inconsciente) de se viver atrás das grades, aguentando todas as demandas sociais "só para não ser livre", para não passar pela dor da travessia de purificação e de independência que ambas as narradoras pareceram atravessar justamente através da arte - arte essa, diga-se de passagem, feita por um outro alguém, ora conhecido e inserido como um outro oposto de si, como Janair; ora um pintor de fato renomado, como Klee.

Essa reflexão parecia estar na própria ideia de Clarice sobre arte e representação. Conforme exposto no início deste texto, quando requerida para fazer seu autorretrato, Clarice aponta para os retratos que outros pintores fizeram dela. O que os outros pintaram sobre ela parece ser, de acordo com sua atitude, o que a retrataria mais autenticamente; o 
que o outro representa sobre nós é o que somos de mais verdadeiro. Nesse jogo entre eu, outro e mundo, que permeia toda a obra clariceana, nem a escritora, nem seus personagens, parecem estarem livres das amarras do estranho - afinal, parece ser ele quem nos oferece a tão apavorante emancipação da medíocre sociedade, principalmente a partir da visão. E a arte, com ou sem o intermédio da palavra - afinal, é por esse meio que a autora (e as protagonistas dos textos aqui tratados) nos comunica toda essa experiência, pois escrever, como já mencionado, "é procurar entender, é procurar reproduzir o irreproduzível" (LISPECTOR, 1999, p. 134) -, parece ser o elemento central para a conquista do que Clarice denomina como a tentativa de "purificação", de "libertação" e de "tornar-se inocente" (LISPECTOR, 1999, p. 228) perante o mundo.

\section{Referências}

ANDRADE, Mário de. Do desenho. In: Aspectos das artes plásticas no Brasil. São Paulo: Livraria Martins Editora, 1965. p. 71-77.

DIDI-HUBERMAN, Georges. O que vemos, o que nos olha. São Paulo: Editora $34,2010$.

KAHN, Daniela Mercedes. A via crucis do outro: identidade e alteridade em Clarice Lispector. São Paulo: Associação Editorial Humanitas: FAPESP, 2005.

LISPECTOR, Clarice. A descoberta do mundo. Rio de Janeiro: Rocco, 1999. . Amor. In: Todos os contos. Rio de Janeiro: Rocco, 2016. p. 145-155. . A paixão segundo G.H.. Rio de Janeiro: Rocco, 2009.

. Literatura de vanguarda no Brasil. In: Outros escritos. Rio de Janeiro: Rocco, 2005. p. 95-111.

OLIVEIRA, Solange Ribeiro de. A paixão segundo G.H.: uma leitura ideológica. In: A paixão segundo G.H.: edição crítica. Madrid; Paris; México; Buenos Aires; São Paulo; Rio de Janeiro; Lima: ALLCA XX, 1996. p. 342-349.

OLIVEIRA, Solange Ribeiro de. Literatura e artes plásticas: o Künstlerroman na ficção contemporânea. Ouro Preto, Minas Gerais: Editora na UFOP, 1993.

PONTIERI, Regina. Clarice Lispector: uma poética do olhar. São Paulo: Ateliê Editorial, 2001.

ROSENBAUM, Yudith. Metamorfoses do mal: uma leitura de Clarice Lispector. São Paulo: Editora da Universidade de São Paulo: FAPESP, 2006. 
SOUSA, Carlos Mendes de. Clarice Lispector: Pinturas. Rio de Janeiro: Rocco, 2013.

SOUZA, Gilda de Mello e. O vertiginoso relance. In: Exercícios de leitura. São Paulo: Duas Cidades, 1980. p. 79-91.

\title{
THE VISUAL DIMENSION IN CLARICE LISPECTOR
}

\begin{abstract}
This article aims to compare the visuality in two texts of Clarice Lispector: the crônica "Medo da libertação" and the novel The Passion According to G.H. - focusing specifically in Janair's wall painting. In both works, the artistic modalities that are presented seem to have an important role to the narrators, in how they understand not only themselves, but the Other and the bourgeois world that imprisons them, giving both narrators the necessary strength to follow the way of the (fearful) freedom.
\end{abstract}

\section{Keywords}

Clarice Lispector. Visuality. Otherness. The passion according to G.H.. "Medo da libertação". 